\title{
A comparison of disease impact according to the cardiometabolic risk profile in psoriatic arthritis
}

Rubén Queiro, Lilyan Charca, Marina Pino

Rheumatology Department and ISPA Translational Immunology Section, Hospital Universitario Central de Asturias (HUCA), Oviedo, Spain

Submitted: 31 July 2020; Accepted: 10 January 2021;

Online publication: 26 February 2021

Arch Med Sci 2021; 17 (2): 557-560

DOI: https://doi.org/10.5114/aoms/132315

Copyright $\odot 2021$ Termedia \& Banach

Psoriasis and psoriatic arthritis (PsA) are chronic inflammatory immune-mediated entities that affect a substantial proportion of the Western population. In both entities, different comorbid conditions are reported, of which the most relevant and frequent are those of cardiovascular type [1, 2]. Cardiometabolic comorbidity (CC) is an important prognostic factor and is also associated with poorer responses and lower drug retention rates in psoriatic disease $[1,2]$. However, the information we currently have about the relationship between $\mathrm{CC}$ and the negative impact of the disease on quality of life is scarce. Hence, our objective was to analyze the relationship between disease impact and CC in long-lasting PsA patients undergoing systemic treatment.

Post hoc analysis of the MAAPS (Minimal Activity in Psoriatic Arthritis) study (Spanish acronym for minimal activity in PsA) was performed. The main results, methodological details, and ethical considerations of the MAAPS study have been published elsewhere [3]. For the assessment of disease impact on patients' lives, we used the 12-item Psoriatic Arthritis Impact of Disease (PsAID-12) questionnaire [4]. The PsAID-12 includes the following items: pain, fatigue, skin problems, work and leisure, disability for daily activity, the sensation of discomfort and irritation, sleep difficulties, disease coping, anxiety and uncertainty, embarrassment, social participation and depression. Each item has a particular weight, and the global score ranges from 0 (best status) to 10 (worst status). A PsAID score below 4 is established as a low disease impact (LDI) status [4]. According to goodness of fit tests, Student's $t$-test, the Mann-Whitney $U$ test, and the Kruskal-Wallis $\mathrm{H}$-test were used to compare quantitative variables, and Pearson's $\chi^{2}$ test or Fisher's exact tests was used for qualitative variables. Data were analyzed using SPSS V19.0 statistical software.

A total of 227 patients were included but a complete data set was available for 223 patients. Among the latter, 122 (54.7\%) were in LDI status. Mean time of disease evolution was not significantly different between LDI (9.6 \pm 7.9 years) and non-LDI patients ( $9.7 \pm 7.7$ years). On the other hand, mean age was not different between the LDI $(54.5 \pm 12.7$ years) and non-LDI group ( $51.7 \pm 12.1$ years). Table I shows the clinical characteristics of patients with a low and high disease impact.

At the study visit, $75.4 \%$ of LDI patients were receiving conventional disease-modifying antirheumatic drugs (DMARD) compared to $76.2 \%$ among non-LDI subjects, while $45.9 \%$ of LDI patients were on biologic drugs (mostly TNF- $\alpha$ inhibitors) compared to $52.5 \%$ of non-LDI.

\author{
Corresponding author: \\ Rubén Queiro PhD \\ Rheumatology Department \\ and ISPA \\ Translational Immunology \\ Section \\ Hospital Universitario \\ Central de Asturias (HUCA) \\ Oviedo, Spain \\ E-mail: rubenque7@yahoo.es
}


Table I. Disease features between patients with low and high disease impact

\begin{tabular}{|c|c|c|}
\hline Parameter & $\begin{array}{l}\text { Low disease impact } \\
\text { (PsAID }<4), N=122\end{array}$ & $\begin{array}{l}\text { High disease impact } \\
(\text { PsAID } \geq 4), N=101\end{array}$ \\
\hline Male, $n(\%)$ & $70(57.4)$ & $51(50.5)$ \\
\hline Age, mean (SD) [years] & $54.5(12.7)$ & $51.7(12.1)$ \\
\hline BMI, mean (SD) $\left[\mathrm{kg} / \mathrm{m}^{2}\right]$ & $27.1(3.9)$ & $26.4(4.8)$ \\
\hline CRP mean (SD) $[\mathrm{mg} / \mathrm{l}]$ & $2.8(3.3)$ & $4.6(8.4)$ \\
\hline \multicolumn{3}{|l|}{ PsA clinical patterns, $n(\%)$ : } \\
\hline Axial & $3(2.5)$ & $4(4.0)$ \\
\hline Peripheral & $107(87.7)$ & $79(78.2)$ \\
\hline Mixed & $12(9.8)$ & $18(17.8)$ \\
\hline DIP disease & $45(36.9)$ & $48(47.5)$ \\
\hline \multicolumn{3}{|l|}{ Familial history, $n(\%)$ : } \\
\hline Psoriasis & $60(49.2)$ & $51(50.5)$ \\
\hline PsA & $11(9.0)$ & $16(15.8)$ \\
\hline PsA duration, mean (SD) [years] & $9.6(7.9)$ & $9.7(7.7)$ \\
\hline Skin symptoms duration, mean (SD) [years] & $21.6(14.5)$ & $22.9(15.0)$ \\
\hline Articular symptoms duration, mean (SD) [years] & $11.9(8.7)$ & $12.6(10.0)$ \\
\hline \multicolumn{3}{|l|}{ Radiologic findings, $n(\%)$ : } \\
\hline Erosions in hands & $40(32.8)$ & $43(43.6)$ \\
\hline Erosions in feet & $33(27.0)$ & $32(31.7)$ \\
\hline PASI, mean (SD) & $1.2(3.8)$ & $1.8(3.2)$ \\
\hline HAQ, mean (SD) & $0.2(0.3)$ & $0.9(0.6)$ \\
\hline $\mathrm{HAQ} \leq 0.5, n(\%)$ & $104(85.2)$ & $33(32.7)$ \\
\hline MDA, $n(\%)$ & $76(62.3)$ & $31(30.7)$ \\
\hline
\end{tabular}

PSAID - psoriatic arthritis impact of disease, SD - standard deviation, BMI - body mass index, CRP - C-reactive protein, DIP - distal interphalangeal joint disease, PASI - psoriasis area and severity index, HAQ - Health Assessment Questionnaire, MDA - minimal disease activity. ${ }^{*} p<0.05,{ }^{* *} p<0.001$

There were more smokers (almost 25\%) among non-LDI compared to LDI patients (13\%), $p=$ 0.083 . The habitual consumption of alcohol was similar in both groups (LDI: $8 \%$ vs. non-LDI: $9 \%$ ). There was a similar percentage of patients having sedentary lifestyle among those who reached and did not reach an LDI (30.3\% vs. 28.7\%). Among patients who reached an LDI, $42.6 \%(n=52)$ did not present CC factors, 33 (27\%) had one, 16 (13\%) had two, 11 (9.0\%) had three and the remaining $8.2 \%(n=10)$ had four or more CC factors. The number of CC factors was not different between the two groups.

Arterial hypertension occurred in $27 \%$ of LDI compared to $26.7 \%$ of non-LDI patients. With respect to diabetes, almost $10 \%$ of patients in LDI status were diabetic compared to $9 \%$ of non-LDI. The distribution of dyslipidemia was similar in both groups (33\% vs. $29 \%$ ). There were more cases of hyperuricemia among LDI patients (15\%) vs. nonLDI subjects (11\%), $p=$ NS. There was also a higher percentage of obese patients among those who reached the LDI status ( $24.6 \%$ vs. $15.8 \%$ ), $p=\mathrm{NS}$. Mean duration of the different cardiovascular comorbid factors was not statistically different between patients with and without LDI. There was a significantly higher frequency of coronary heart disease among LDI subjects (6.6\% vs. $1 \%, p=0.035$; crude OR $=7.02,95 \% \mathrm{Cl}: 0.86-57.1, p=0.068)$. Table II shows the distribution of CC factors between patients with low and high disease impact. Table III displays similar information by age group.

With the exception of smoking, we found no clear association between disease impact and CC. The prevalence of coronary heart disease was even higher among patients who had reached an LDI situation. Among the CC factors evaluated, the only one that was more prevalent among patients 
Table II. Distribution of cardiovascular risk factors between patients with low and high disease impact ( $n(\%))$

\begin{tabular}{|c|c|c|c|}
\hline CV risk factors & $\begin{array}{l}\text { Low disease impact }(\text { PsAID < 4) } \\
\qquad N=122\end{array}$ & $\begin{array}{l}\text { High disease impact } \\
(\text { PsAID } \geq 4) N=101\end{array}$ & $P$-value \\
\hline Dyslipidemia & $40(32.8)$ & $29(28.7)$ & 0.512 \\
\hline Hypertension & $33(27.0)$ & $27(26.7)$ & 0.958 \\
\hline *Obesity & $30(24.6)$ & $16(15.8)$ & 0.108 \\
\hline Diabetes & $12(9.8)$ & $9(8.9)$ & 0.814 \\
\hline${ }^{* \star}$ Smoking & $16(13.1)$ & $25(24.8)$ & 0.083 \\
\hline
\end{tabular}

Table III. Distribution of cardiometabolic risk factors and disease outcomes by age groups

\begin{tabular}{|lccccc|}
\hline Variable & $\begin{array}{c}<40 \\
n=31\end{array}$ & $\begin{array}{c}40-49 \\
n=61\end{array}$ & $\begin{array}{c}50-65 \\
n=60\end{array}$ & $\begin{array}{c}>65 \\
n=75\end{array}$ & $P$-value \\
\hline Disease duration, mean (SD) [years] & $6.2(5.4)$ & $8(5.8)$ & $8.4(7.5)$ & $13.3(8.9)$ & $<0.001$ \\
\hline Smokers (\%) & 29 & 21.3 & 21.7 & 8 & 0.020 \\
\hline Dyslipidemia (\%) & 12.9 & 24.6 & 31.7 & 41.3 & 0.016 \\
\hline Hypertension (\%) & 0 & 9.8 & 26.7 & 53.3 & $<0.001$ \\
\hline Obesity (\%) & 12.9 & 14.8 & 26.7 & 25.3 & NS \\
\hline Diabetes (\%) & 0 & 0 & 11.7 & 21.3 & $<0.001$ \\
\hline DAPSA rem. (\%) & 25.9 & 33.3 & 20 & 29.3 & NS \\
\hline PSAID < 4 (\%) & 10.7 & 27 & 24.6 & 37.7 & $<0.05^{*}$ \\
\hline
\end{tabular}

SD - standard deviation, DAPSA - Disease Activity index for PSoriatic Arthritis, Rem - remission, PsAID - Psoriatic Arthritis Impact of Disease. A PSAID < 4 defines a low disease impact. *Patients aged $>65$ versus patients aged $<40$.

who did not achieve the LDI status was smoking. Thus, PsA smokers had decreased odds of reaching a low-impact disease by $54 \%$ (crude OR $=0.46$, 95\% Cl: 0.22-0.94, $p=0.032$ ). Moreover, patients over 65 years of age had the lowest smoking rate (8\%) but at the same time the highest frequency of an LDI state (37.7\%). In contrast, patients younger than 40 years had the highest smoking rate (29\%) but the lowest frequency of an LDI state (10.7\%). All this is in keeping with the results of the Danish nationwide DANBIO registry in which PSA smokers had worse baseline patient-reported outcomes, shorter treatment adherence and poorer response to TNF- $\alpha$ blockers compared to non-smokers [5].

The concept of disease impact is multidimensional and may encompass various aspects that patients may relate or not to the effectiveness of treatments or the comorbidities linked to the disease [6]. This should lead us to a cautious interpretation of the results of our study, but also of those other studies that associate a benefit in the intervention on CC factors and PsA outcomes [7-10].

Our study has the limitations of a cross-sectional study, and perhaps it is not the most appropriate to test the association between CC and the impact of the disease measured by the PsAID. However, the information provided here has the strengths of a multicenter representative sample of patients treated under real-practice conditions.

With the exception of smoking, we found no clear association between CC and disease impact. All in all, patients with PsA should be encouraged and oriented to maintain healthy cardiovascular habits.

\section{Acknowledgments}

MAAPs (Minimal Activity in Psoriatic Arthritis) Study Group: J.D. Cañete (H. Clinic, Barcelona, Spain); C. Montilla (HU. Salamanca, Salamanca, Spain); M.A. Abad (H. Virgen del Puerto, Plasencia, Spain); S. Gómez (Pfizer Medical Department, Madrid, Spain); M. Montoro (Pfizer Medical Department, Madrid, Spain); A. Cabez (Pfizer Medical Department, Madrid, Spain); J.C. Torre Alonso (H. Monte Naranco, Oviedo, Spain); J.A. Román-Ivorra (Hospital Universitario (HU) La Fe, Valencia, Spain); J. Sanz (HU Puerta de Hierro, Madrid, Spain); J. Salvatierra (HU San Cecilio, Granada, Spain); J. Calvo-Alén (HU Sierrallana, Torrelavega, Spain); A. Sellas (HU Vall d'Hebron, Barcelona, Spain); F.J. Rodriguez (H. Santa Lucia, Cartagena, Spain); A. Bermúdez (HU Virgen de la Arrixaca, Murcia, Spain); M. Romero (Complejo hospitalario 
Jaén, Spain); M. Riesco (H. Juan Ramón Jiménez, Huelva, Spain); J.C. Cobeta (H. Royo Villanova, Zaragoza, Spain); F. Medina (H. Puerta del Mar, Cádiz, Spain); A. Aragón (H. Getafe, Madrid, Spain); M.L. García (HU Basurto, Bilbao, Spain); A. Urruticoechea (H. Can Misses, Ibiza, Spain); C.M. González (HU Gregorio Marañón, Madrid, Spain); E. Judez (HU, Albacete, Spain); B. González (HU Nta. Sra de la Candelaria, Tenerife, Spain); P. Fernández (HU 12 de Octubre, Madrid, Spain); L. Pantoja (H. del Bierzo, Leon, Spain); R. Morlá (H. Sant Pau y Sta. Tecla, Tarragona, Spain).

The MAAPs study was funded by Pfizer.

\section{References}

1. Krakowski P, Gerkowicz A, Pietrzak A, et al. Psoriatic arthritis - new perspectives. Arch Med Sci 2019; 15: 580-9.

2. Pietrzak A, Chabros P, Grywalska E, et al. Serum lipid metabolism in psoriasis and psoriatic arthritis - an update. Arch Med Sci 2019; 15: 369-75.

3. Queiro R, Cañete JD, Montilla C, et al. Minimal disease activity and impact of disease in psoriatic arthritis: a Spanish cross-sectional multicenter study. Arthritis Res Ther 2017; 19: 72

4. Gossec L, de Wit M, Kiltz U, et al. A patient-derived and patient-reported outcome measure for assessing psoriatic arthritis: elaboration and preliminary validation of the Psoriatic Arthritis Impact of Disease (PsAID) questionnaire, a 13-country EULAR initiative. Ann Rheum Dis 2014; 73: 1012-9.

5. Højgaard P, Glintborg B, Hetland ML, et al. Association between tobacco smoking and response to tumour necrosis factor alpha inhibitor treatment in psoriatic arthritis: results from the DANBIO registry. Ann Rheum Dis 2015; 74: 2130-6.

6. Queiro R, Cañete JD, Montilla C, et al. Very low disease activity, DAPSA remission, and impact of disease in a Spanish population with psoriatic arthritis. J Rheumatol 2019; 46: 710-15.

7. Batalla A, González-Fernández D, González-Lara L, et al. Cardiovascular risk factors influence response to biological therapies in psoriasis. J Am Acad Dermatol 2015; 73: 327-9.

8. Almodóvar R, Zarco P, Otón T, et al. Effect of weight loss on activity in psoriatic arthritis: a systematic review. Reumatol Clin 2018; 14: 207-10.

9. Queiro R, Cañete JD. Impact of cardiovascular risk factors on the achievement of therapeutic goals in psoriatic arthritis: is there any association? Clin Rheumatol 2018; 37: 661-6.

10. Cañete JD, Tasende JAP, Laserna FJR, et al. The impact of comorbidity on patient-reported outcomes in psoriatic arthritis: a systematic literature review. Rheumatol Ther 2020 Apr 8. doi: 10.1007/s40744-020-00202-x 